\title{
Post-diagnosis hemoglobin change associates with overall survival of multiple malignancies - results from a 14-year hospital-based cohort of lung, breast, colorectal, and liver cancers
}

\author{
Shaogui Wan ${ }^{1}$, Yinzhi Lai ${ }^{1}$, Ronald E Myers ${ }^{1}$, Bingshan Li ${ }^{3}$, Juan P Palazzo ${ }^{2}$, Ashlie L Burkart ${ }^{2}$, Guokai Chen ${ }^{4}$,
} Jinliang Xing ${ }^{5}$ and Hushan Yang ${ }^{1 *}$

\begin{abstract}
Background: Anemia refers to low hemoglobin $(\mathrm{Hb})$ level and is a risk factor of cancer patient survival. The National Comprehensive Cancer Network recently suggested that post-diagnosis $\mathrm{Hb}$ change, regardless of baseline Hb level, indicates the potential presence of anemia. However, there is no epidemiological study evaluating whether $\mathrm{Hb}$ change has direct prognostic values for cancer patients at the population level.

Methods: We identified 6675 patients with a diagnosis of primary lung, breast, colorectal, or liver cancer who visited the Kimmel Cancer Center at the Thomas Jefferson University from 1998 to 2011. All patients had at least two Hb measurements within the first six months after diagnosis. We analyzed the main, dose-dependent, and time-dependent effects of $\mathrm{Hb}$ changes on patient survival.

Results: Compared to patients with a low $\mathrm{Hb}$ change $(|\Delta \mathrm{Hb}| \leq 2.6)$, those having a $|\Delta \mathrm{Hb}|>2.6$ exhibited a significantly shorter survival (hazard ratio $=1.40,95 \%$ confidence interval $1.31-1.50, P=4.5 \times 10^{-22}, P_{\log \text { rank }}=1.6 \times 10^{-39}$ ). This association remained significant across the four cancer types. Bootstrap resampling validated these findings $100 \%$ of the time with $P<0.01$ in all patients and in patients of individual cancers. The association exhibited an apparent U-shape dosedependent pattern. Time-dependent modeling demonstrated that the effect of $\mathrm{Hb}$ change on the survival of the overall patient population persisted for approximately 4.5 years after diagnosis.
\end{abstract}

Conclusion: Post-diagnosis $\mathrm{Hb}$ change associates with the survival of multiple cancers and may have clinical values in tailoring anti-anemia treatments. Because $\mathrm{Hb}$ level is frequently measured during cancer treatment, $\mathrm{Hb}$ changes may be a potentially important variable in building cancer prognosis models.

Keywords: Hemoglobin, Survival, Prognosis

\section{Background}

Anemia is a condition that develops when whole blood lacks sufficient healthy red blood cells or hemoglobin $(\mathrm{Hb})$, an oxygen-carrying protein within red blood cells. Cancer-associated anemia is one of the most common paraneoplastic syndromes during cancer progression or treatment and is prevalent in $30 \%$ to $90 \%$ of cancer patients [1]. Although anemia incidence varies with cancer

\footnotetext{
* Correspondence: hushan.yang@jefferson.edu

'Division of Population Science, Department of Medical Oncology, Kimmel Cancer Center, Thomas Jefferson University, Philadelphia, PA 19107, USA Full list of author information is available at the end of the article
}

types, stages and patient characteristics, it has been estimated that over $40 \%$ of all cancer patients are anemic at diagnosis, a rate that increases by an additional $40 \%$ after chemotherapy or radiation therapy treatments [1-4]. Because cancer-associated anemia has been documented as an adverse prognostic factor as well as predictor of treatment response, [5,6] evaluations of anemia and anti-anemia treatments have significant clinical implications.

The diagnosis and treatment of anemia are influenced by various factors, such as hemorrhage, hemolysis, nutritional deficiency, hereditary disease, renal dysfunction,

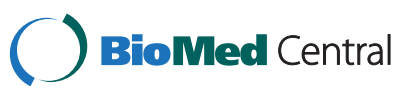


and systemic chemotherapy or radiation therapy $[7,8]$. Since clinical symptoms of anemia start slowly, Hb level is currently the most important predictor in guiding anemia evaluation and treatment, regardless of the underlying causes [3]. Correction of cancer-associated anemia is usually achieved by blood transfusion with packed red blood cells (PRBCs) or erythropoiesis-stimulating agents (ESAs). However, considerable controversy regarding the safety and restrictions on the correction modality of cancer-associated anemia has been recently reported. For instance, several recent meta-analysis studies reported that ESA administrations, while reducing the incidence of clinically defined anemia, may confer an adverse survival to patients exhibiting a large change in $\mathrm{Hb}$ levels during treatment [9-12]. In comparison, other studies did not identify such significant effects of ESA use on patient mortality $[13,14]$. These studies suggested the complexity in the diagnosis and tailored treatment of anemia in the context of broad variations in Hb levels.

Given the wide variations in $\mathrm{Hb}$ level among cancer patients and even healthy individuals, it is impractical to define a clinically universal "normal" $\mathrm{Hb}$ value. Moreover, during anti-anemia treatment in clinics, it remains controversial as to the time to start initial treatment and the targeted range of $\mathrm{Hb}$ levels. For example, the baseline $\mathrm{Hb}$ values that trigger ESA treatment for patients with cancer- or therapy-induced anemia range from 8 to $11 \mathrm{~g} / \mathrm{dL}$ under different practice guidelines [3,15-18]. The newly updated National Comprehensive Cancer Network (NCCN) guideline suggests that in non-anemic patients with a high baseline $\mathrm{Hb}$ level, a drop of $2 \mathrm{~g} / \mathrm{dL}$ or more should be evaluated for the presence of anemia [3]. This raises the question whether a change in $\mathrm{Hb}$ levels during follow-up or treatment, regardless of baseline or single time point $\mathrm{Hb}$ levels, can directly predict patient prognosis. In the present study, we sought to utilize a large hospital-based cancer patient cohort to comprehensively evaluate post-diagnosis $\mathrm{Hb}$ change $(\Delta \mathrm{Hb})$ as a predictor of overall survival in patients with lung, breast, colorectal, or liver cancer, four of the most common causes of cancer-related deaths. To the best of our knowledge, this is the first population-based epidemiological study that evaluates $\mathrm{Hb}$ changes (either an increase or a decrease) in association with cancer patient prognosis.

\section{Methods}

\section{Study population}

Subjects in this study were identified from a hospitalbased cohort of patients with histologically confirmed primary lung, breast, colorectal, or liver cancer, who visited the Kimmel Cancer Center at Thomas Jefferson University with an initial diagnosis date from 1998 to 2011. For this analysis, a total of 6675 patients were included who had at least two Hb measurements within the first six months after primary cancer diagnosis. This study was approved by the Institutional Review Board of Thomas Jefferson University.

\section{Data collection}

Demographic and clinical data were obtained from medical chart review. Demographic variables included age, gender, and ethnicity. Clinical variables included tumor stage, tumor grade and treatments including surgery, chemotherapy and radiation therapy. The routine clinical laboratory tests of complete blood count panel, including $\mathrm{Hb}$ values and dates of measurement, were obtained from systemic review of electronic medical charts. The maximum and minimum values of $\mathrm{Hb}$ levels within six months after cancer diagnosis were used to calculate $\mathrm{Hb}$ change $(\Delta \mathrm{Hb})$, and the date of $\mathrm{Hb}$ measurements were used to determine the plus or minus sign of $\Delta \mathrm{Hb}$. When the minimum value was measured before the maximum value, the sign of $\Delta \mathrm{Hb}$ was plus, indicating an increase in $\mathrm{Hb}$ level. Otherwise, the sign of $\Delta \mathrm{Hb}$ was minus, indicating a decrease in $\mathrm{Hb}$ level.

\section{Statistical analysis}

The clinical endpoint analyzed in this study was overall survival of cancer patients. Overall survival time was defined as the time from initial cancer diagnosis to death from any cause or last follow-up. Patients who were alive at last follow-up were censored for analysis. The associations between $\Delta \mathrm{Hb}$ and overall survival were estimated using hazard ratio (HR) and 95\% confidence interval (95\% CI) calculated by multivariate Cox proportional hazards model, adjusting for age, gender, ethnicity, tumor stage, tumor grade, surgery, chemotherapy, and radiation therapy, where appropriate. The results of the main effects analyses were internally validated using the bootstrap resampling method [19]. A total of 100 bootstrap samples were generated for each analysis. Each time, a bootstrap sample was drawn from the original dataset and the $P$ value for the analysis was calculated. The number of times with a $P$ value $<0.01$ was counted. Dose-dependent analyses were conducted, assuming $\Delta \mathrm{Hb}$ as both a categorical and a continuous variable, by multivariate Cox proportional hazards model and fractional polynomial regression model, respectively, adjusting for age, gender, ethnicity, tumor stage, tumor grade, surgery, chemotherapy, and radiation therapy [20]. The distributions of absolutely changed $\mathrm{Hb}$ values between gender and cancer sites were compared by Student's $t$ test. Time-dependent analyses were conducted using flexible parametric modeling framework that analyzes the interaction between $\Delta \mathrm{Hb}$ and survival time, and confers a time-dependent effect of $\Delta \mathrm{Hb}$ on patient survival adjusting for other host and clinical variables 
[21]. Survival curves were constructed using the KaplanMeier method and compared using the log rank test with anemia indicated by a Hb level of less than $12 \mathrm{~g} / \mathrm{dL}$ [3]. Statistical analyses in this study were conducted using SAS 9.2 (SAS Institute, Cary, NC) and STATA 12.0 (STATA Corp., College Station, TX) software packages. All $P$ values were 2 -sided. $P \leq 0.05$ was considered statistical significant.

\section{Results}

Characteristics of study population

A total of 6675 cancer patients were included in the analysis for this study, with an average age of 62.4 ( \pm standard deviation, 11.3) years. The distributions of host variables were summarized in Table 1 . There were 2367 lung cancer patients, 1739 breast cancer patients, 1860 colorectal cancer (CRC) patients, and 709 liver cancer

Table 1 Characteristics of the study population

\begin{tabular}{|c|c|c|c|c|c|}
\hline Variables & $\begin{array}{l}\text { All cancers }(n=6675) \\
\text { No. of patients (\%) }\end{array}$ & $\begin{array}{l}\text { Lung ( } n=2367) \\
\text { No. of patients (\%) }\end{array}$ & $\begin{array}{l}\text { Breast }(n=1739) \\
\text { No. of patients (\%) }\end{array}$ & $\begin{array}{l}\text { CRC }(n=1860) \\
\text { No. of patients (\%) }\end{array}$ & $\begin{array}{l}\text { Liver }(n=709) \\
\text { No. of patients (\%) }\end{array}$ \\
\hline Age (Mean \pm SD) & $62.4 \pm 11.3$ & $65.5 \pm 11.3$ & $56.3 \pm 13.3$ & $64.7 \pm 13.8$ & $61.0 \pm 11.3$ \\
\hline \multicolumn{6}{|l|}{ Gender } \\
\hline Female & $4081(61.14)$ & $1232(52.05)$ & 1739(100) & $949(51.02)$ & $161(22.71)$ \\
\hline Male & 2594(38.86) & 1135(47.95) & & $911(48.98)$ & $548(77.29)$ \\
\hline \multicolumn{6}{|l|}{ Ethnicity } \\
\hline Caucasian & $4758(71.28)$ & $1780(75.2)$ & $1123(64.58)$ & $1403(75.43)$ & $452(63.75)$ \\
\hline Black & $1445(21.65)$ & $468(19.77)$ & $491(28.23)$ & $359(19.3)$ & $127(17.91)$ \\
\hline Others & $472(7.07)$ & $119(5.03)$ & 125(7.19) & $98(5.28)$ & 130(18.33) \\
\hline \multicolumn{6}{|l|}{ Tumor stages } \\
\hline Stage 0 & $325(4.87)$ & $1(0.04)$ & 264(15.18) & $60(3.23)$ & \\
\hline Stage 1 & $1764(26.43)$ & $533(22.52)$ & 605(34.79) & $419(22.53)$ & $207(29.2)$ \\
\hline Stage 2 & $1272(19.06)$ & $158(6.68)$ & $527(30.3)$ & $454(24.41)$ & 133(18.76) \\
\hline Stage 3 & $1207(18.08)$ & $465(19.65)$ & $164(9.43)$ & $418(22.47)$ & $160(22.57)$ \\
\hline Stage 4 & $1659(24.85)$ & $1042(44.02)$ & $119(6.84)$ & $385(20.7)$ & 113(15.94) \\
\hline Unknown & $448(6.71)$ & 168(7.09) & $60(3.45)$ & $124(6.67)$ & $96(13.54)$ \\
\hline \multicolumn{6}{|l|}{ Tumor grades } \\
\hline Well & $515(7.71)$ & $124(5.24)$ & 155(8.91) & $172(9.25)$ & $64(9.03)$ \\
\hline Moderately & $2260(33.86)$ & $427(18.04)$ & $575(33.06)$ & 1138(61.18) & $120(16.93)$ \\
\hline Poorly & 1514(22.68) & $630(26.62)$ & $605(34.79)$ & $250(13.44)$ & $29(4.09)$ \\
\hline Not determined & $2386(35.75)$ & $1186(50.1)$ & $404(23.23)$ & $300(16.13)$ & 496(69.96) \\
\hline \multicolumn{6}{|l|}{ Chemotherapy } \\
\hline No & 2258(33.83) & $258(10.9)$ & $989(56.87)$ & $918(49.35)$ & $93(13.12)$ \\
\hline Yes & $2865(42.92)$ & $948(40.05)$ & $705(40.54)$ & $840(45.16)$ & $372(52.47)$ \\
\hline Unknown & 1552(23.25) & $1161(49.05)$ & $45(2.59)$ & $102(5.48)$ & $244(34.41)$ \\
\hline \multicolumn{6}{|l|}{ Radiation } \\
\hline No & 2933(43.94) & 208(8.79) & 1097(63.08) & 1492(80.22) & 136(19.18) \\
\hline Yes & 1929(28.9) & $970(40.98)$ & $582(33.47)$ & $335(18.01)$ & $42(5.92)$ \\
\hline Unknown & 1813(27.16) & $1189(50.23)$ & $60(3.45)$ & $33(1.77)$ & $531(74.89)$ \\
\hline \multicolumn{6}{|l|}{ Surgery } \\
\hline No & 1134(16.99) & 615(25.98) & $95(5.46)$ & 210(11.29) & 214(30.18) \\
\hline Yes & 4832(72.39) & $1200(50.7)$ & 1644(94.54) & 1650(88.71) & $338(47.67)$ \\
\hline Unknown & $709(10.62)$ & $552(23.32)$ & & & 157(22.14) \\
\hline \multicolumn{6}{|l|}{ Vital status } \\
\hline Alive & $3133(46.94)$ & $572(24.17)$ & 1374(79.01) & $986(53.01)$ & $201(28.35)$ \\
\hline Dead & $3542(53.06)$ & 1795(75.83) & $365(20.99)$ & 874(46.99) & $508(71.65)$ \\
\hline
\end{tabular}


patients, with an average age of $65.5( \pm 11.3), 56.3( \pm$ 13.3), 64.7 ( \pm 13.8$)$, and 61.0 ( \pm 11.3$)$, respectively. In all cancer patients, a relatively similar distribution of patients was observed among stages 1 to 4 (from $18.08 \%$ to $26.43 \%)$. The majority of patients had moderately $(33.86 \%)$ or poorly (22.68\%) differentiated tumors. Most patients received surgical resection (72.39\%), especially those with breast (94.54\%) and colorectal cancers (88.71\%). Approximately $43 \%$ of patients received chemotherapy with a relatively similar distribution across the four cancer types. About $28.9 \%$ of patients received radiation therapy. The median follow-up time of all patients in this study was 26.8 months (quartile range, 8.8-69.4) and the median survival time of censored patients was 58.7 months (quartile range, 26.2-100.4). Figure 1 shows the distribution of absolute $\Delta \mathrm{Hb}(|\Delta \mathrm{Hb}|)$ in different cancers by gender status. A borderline significant difference between male and female patients was noticed in lung $(P=0.056)$ and colorectal $(P=0.096)$, but not liver cancer patients $(P=0.850)$. The $|\Delta \mathrm{Hb}|$ value in breast cancer patients was significantly lower than that of the female patients of the other three cancers with $P<0.0001$.

\section{Post-diagnosis $\mathrm{Hb}$ changes and the overall survival of cancer patients}

The associations between $\Delta \mathrm{Hb}$ and patient survival were estimated by multivariate Cox proportional hazard model. First, we analyzed $|\Delta \mathrm{Hb}|$ and overall survival in all cancer patients as well as in patients with individual cancers using a median cut-off value of $2.6 \mathrm{~g} / \mathrm{dL}$ measured in all cancer patients. As shown in Table 2, patients with a higher level of $|\Delta \mathrm{Hb}|$ exhibited a significantly poorer survival, compared to those with a low $|\Delta \mathrm{Hb}|$ level, with an HR of 1.40 (95\% CI 1.31-1.50, $P=4.5 \times 10^{-22}$, $\left.P_{\log \text { rank }}=1.6 \times 10^{-39}\right)$. Similar results were found in patients with either a decreased $\mathrm{Hb}(\Delta \mathrm{Hb}<-2.6)(\mathrm{HR}=1.35$, 95\% CI $1.25-1.46, P=3.0 \times 10^{-15}$ ) or an increased $\mathrm{Hb}$ $(\Delta \mathrm{Hb}>2.6)\left(\mathrm{HR}=1.53,95 \% \mathrm{CI} 1.39-1.69, P=5.7 \times 10^{-18}\right)$. The significant association between $|\Delta \mathrm{Hb}|$ and patient survival remained prominent across the four cancer types included in this study, with an HR (95\% CI, $P$ value, log rank $P$ value $)$ of $1.32\left(1.20-1.46, P=2.7 \times 10^{-8}, P_{\log \text { rank }}=\right.$ $\left.8.9 \times 10^{-4}\right), 1.49\left(1.19-1.86, P=4.3 \times 10^{-4}, P_{\log \text { rank }}=6.5 \times 10^{-10}\right)$, $1.46\left(1.27-1.68, P=7.9 \times 10^{-8}, P_{\log \text { rank }}=4.6 \times 10^{-8}\right)$, and 1.45 (1.20-1.74, $P=7.9 \times 10^{-5}, P_{\log \text { rank }}=1.6 \times 10^{-2}$ ) for lung, breast, colorectal, and liver cancer, respectively. Kaplan Meier analysis demonstrated a significantly different overall survival time between patients with higher- and lower-thanmedian $|\Delta \mathrm{Hb}|$ in all cancer patients as well as in patients with individual cancers (data not shown). We then conducted internal validation using bootstrap resampling and demonstrated that the significant association between $|\Delta \mathrm{Hb}|$ and patient survival was validated $100 \%$ of times in all cancer patients combined, as well as in patients with individual cancer types (Table 2). In concordance with previous reports, anemia at baseline (baseline $\mathrm{Hb}<12 \mathrm{~g} / \mathrm{L}$ ) conferred a significant adverse effect on patient survival (Additional file 1: Table S1). A joint analysis between baseline $\mathrm{Hb}$ level and $\mathrm{Hb}$ change in the combined cohort and individual cancer sites indicated the $\mathrm{Hb}$ changes added

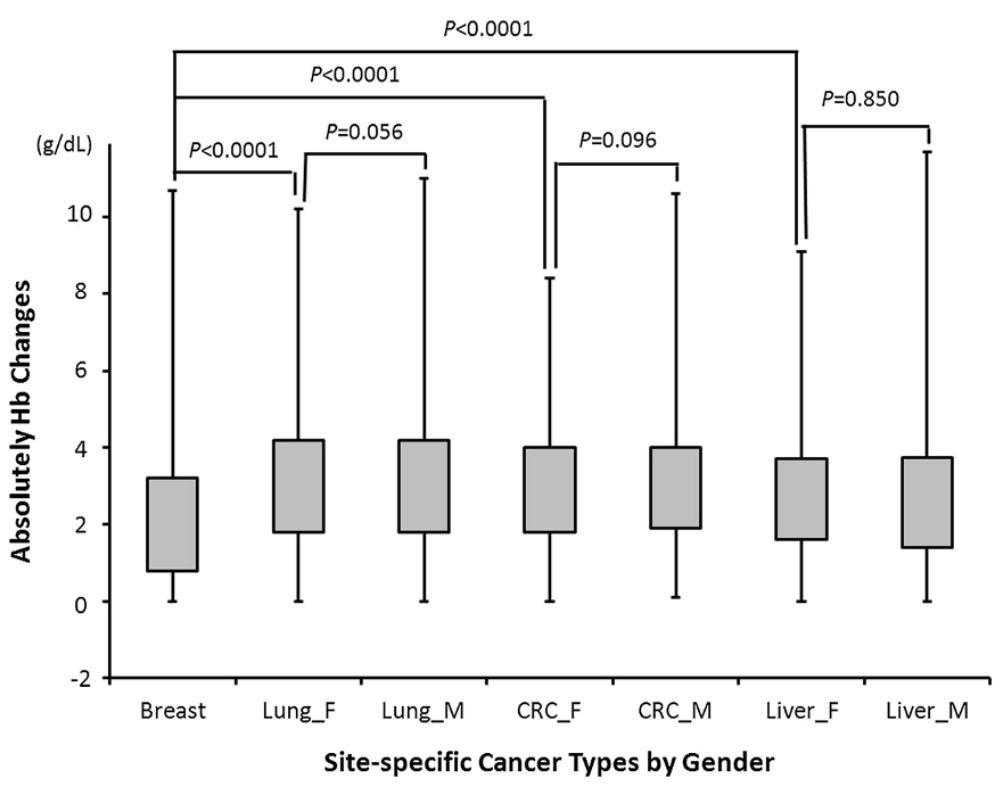

Figure $1 \mathrm{Hb}$ changes in different cancer types by gender. Breast, breast cancer patients, Lung_F, female lung cancer patients; Lung_M, male lung cancer patients; CRC_F, female colorectal cancer patients; CRC_M, male colorectal cancer patients; Liver_F, female liver cancer patients; Liver_M, male liver cancer patients. The grey boxes were quartile range of absolutely $\mathrm{Hb}$ changes from $25-75 \%$, the upper and lower error bars indicated maximum and minimum changed values of $\mathrm{Hb}$, respectively. The indicated groups were compared by Student's $\mathrm{t}$ test. 
Table 2 The association between $\mathrm{Hb}$ changes and the overall survival of cancer patients

\section{Cancers} Hb changes

Dead

Alive

HR $(95 \% \mathrm{CI})^{*}$

$P$ value

All cancers

By $|\triangle \mathrm{Hb}|$

$|\Delta \mathrm{Hb}| \leq 2.6$

1585

$|\Delta \mathrm{Hb}|>2.6$

1957

1831

1302

$1.40(1.31-1.50)$

$4.5 \times 10^{-22}$

100

$1.6 \times 10^{-39}$

By $\triangle \mathrm{Hb}$

\begin{tabular}{|c|c|c|c|}
\hline$-2.6 \leq \Delta \mathrm{Hb} \leq 2.6$ & 1585 & 1831 & 1.00 \\
\hline$\Delta \mathrm{Hb}<-2.6$ & 1357 & 975 & $1.35(1.25-1.46)$ \\
\hline$-1 b>2.6$ & 600 & 27 & $1.53(1.39-1.69)$ \\
\hline
\end{tabular}

Lung cancer

By $|\triangle \mathrm{Hb}|$

$$
\begin{aligned}
& |\Delta H b| \leq 2.6 \\
& |\Delta H b|>2.6
\end{aligned}
$$

756

1039

281

291

1.00

$1.32(1.20-1.46)$

$2.7 \times 10^{-8}$

100

$8.9 \times 10^{-4}$

By $\triangle \mathrm{Hb}$

$-2.6 \leq \Delta \mathrm{Hb} \leq 2.6$
$\Delta H \mathrm{H}<-2.6$
$\Delta \mathrm{Hb}>2.6$

756

281

1.00

1.25 (1.12-1.38)

$3.7 \times 10^{-5}$

97

265

45

1.59 (1.38-1.84)

$1.8 \times 10^{-10}$

100

$2.3 \times 10^{-5}$

Breast cancer

By $|\Delta \mathrm{Hb}|$
$|\Delta \mathrm{Hb}| \leq 2.6$

$|\Delta \mathrm{Hb}|>2.6$

By $\triangle \mathrm{Hb}$
195

170

927

447

195

135

35

$\Delta \mathrm{Hb}>2.6$

Colorectal cancer

By $|\Delta \mathrm{Hb}|$
927

70

$$
|\Delta \mathrm{Hb}| \leq 2.6
$$

$|\Delta \mathrm{Hb}|>2.6$

By $\triangle \mathrm{Hb}$

$-2.6 \leq \Delta \mathrm{Hb} \leq 2.6$
$\Delta \mathrm{Hb}<-2.6$
$\Delta \mathrm{Hb}>2.6$

360

514

360

281

233

Liver cancer

By $|\triangle \mathrm{Hb}|$

$$
|\Delta \mathrm{Hb}| \leq 2.6
$$

$|\Delta \mathrm{Hb}|>2.6$

By $\triangle \mathrm{Hb}$
$-2.6 \leq \Delta \mathrm{Hb} \leq 2.6$
$\Delta \mathrm{Hb}<-2.6$

$\Delta \mathrm{Hb}>2.6$
1.00

1.49 (1.19-1.86)

$4.3 \times 10^{-4}$

100

$6.5 \times 10^{-10}$

1.00

1.45 (1.14-1.84)

0.002

1.65 (1.14-2.40)

0.008

70

58

$1.5 \times 10^{-9}$ 
additional predictive value compared to baseline $\mathrm{Hb}$ alone (Additional file 1: Table S2). For instance, in the overall cohort, compared to patients with high baseline $\mathrm{Hb}$ and small $\mathrm{Hb}$ change, the risk of death was 1.23 (95\% CI 1.091.39), $P=0.0008$, 1.34 (95\% CI 1.19-1.51), $P=1.6 \times 10^{-6}$, and 1.75 (95\% CI 1.58-1.94), $P=4.9 \times 10^{-26}$ ) for those with a high baseline $\mathrm{Hb}$ and large $\mathrm{Hb}$ change, low baseline $\mathrm{Hb}$ and small $\mathrm{Hb}$ change, and low baseline $\mathrm{Hb}$ and large $\mathrm{Hb}$ change, respectively.

\section{Dose-dependent effects of $\mathrm{Hb}$ changes on cancer patient survival}

To evaluate the observed associations between $\Delta \mathrm{Hb}$ and cancer survival in a more dynamic manner, we analyzed the dose-dependent effects of $\Delta \mathrm{Hb}$ as both a categorical and a continuous variable, using Cox proportional hazard models and fractional polynomial regression model, respectively. As shown in Figure 2, a U-shape dosedependent effect was noticed in all cancer patients combined and in patients with individual cancers when $\Delta \mathrm{Hb}$ was treated as a categorical (Figure 2A) or a continuous variable (Figure $2 \mathrm{~B}$ ). These data were highly consistent with that of Table 2, further demonstrating that both significantly increased and decreased $\mathrm{Hb}$ levels were associated with adverse survival of cancer patients.

\section{Time-dependent effects of $\mathrm{Hb}$ changes on cancer patient survival}

We analyzed the time-dependent effects of $|\Delta \mathrm{Hb}|$ on patient survival during follow-up after diagnosis, using a flexible parametric modeling framework adjusting for host and clinical variables (Figure 3). The increased risk of death from all cancers conferred by $|\Delta \mathrm{Hb}|$ reached a peak level at 5.1 months after diagnosis, and remained significant over 54 months (Figure 3A). Similar effects were observed for individual cancers (Figures $3 \mathrm{~B}$ to $3 \mathrm{E}$ ).

\section{Death risk conferred by anemia modulated by $|\Delta \mathrm{Hb}|$}

The association between anemia and cancer mortality is influenced by many factors [8]. To evaluate if $\mathrm{Hb}$ changes modulate the predicative role of anemia in cancer mortality, we analyzed the association between anemia, which was indicated by the average $\mathrm{Hb}$ level measured within six months after diagnosis of less than $12 \mathrm{~g} / \mathrm{dL}$, and the overall survival of all cancer patients in this study stratified by different levels of $|\Delta \mathrm{Hb}|$. In line with previous reports, Kaplan-Meier curves and log rank tests indicated that anemic patients had a much shorter survival (median survival time [MST], 38.2 months) compared with non-anemic patients (MST, 89.2 months) $\left(P_{\log \text { rank }}=6.2 \times 10^{-30}\right)$ (Figure $\left.4 \mathrm{~A}\right)$. This difference remained significant in patients with small $|\Delta \mathrm{Hb}|$. For instance, the MSTs were 140.6 months in non-anemic and 60.2 months in anemic cancer patients with $|\Delta H b| \leq 2$
$\left(P_{\log \text { rank }}=2.1 \times 10^{-13}\right)$ (Figure 4B). In patients with $|\Delta \mathrm{Hb}|$ between 2 and 4 , the MSTs were 74.3 and 38.9 months in non-anemic and anemic patients, respectively $\left(P_{\log \text { rank }}=6.3 \times 10^{-8}\right)$ (Figure $\left.4 \mathrm{C}\right)$. However, in patients with $|\Delta \mathrm{Hb}|>4$, no significant difference was observed between non-anemic (MST, 23.1 months) and anemic (MST, 24.3 months) patients $\left(P_{\log \text { rank }}=0.668\right)$ (Figure 4D). The association exhibited similar patterns after adjusting for all covariates in the main effect analysis (Additional file 2: Figure S1). Moreover, similar trends were observed when the analysis was done in individual cancer sites (Additional file 2: Figure S2). Moreover, the results remained consistent when the analysis was conducted by $\Delta \mathrm{Hb}$ instead of $|\Delta \mathrm{Hb}|$ (Additional file 2: Figure S3). These data indicated that the unfavorable survival conferred by anemia on cancer patients was modulated by $\Delta \mathrm{Hb}$ after patient diagnosis.

\section{Discussion}

In this study, we evaluated the association between $\Delta \mathrm{Hb}$ measured within six months after cancer diagnosis and the overall survival of a large population of 6675 patients of four different solid tumors. Our data indicated that $\mathrm{Hb}$ changes after diagnosis had an adverse effect on the patient survival. The effect was in a dose-dependent manner and could persist over a long period after diagnosis. In addition, $\mathrm{Hb}$ changes seemed to also modulate the elevated risk of death associated with clinically defined anemia in cancer patients.

Many factors may induce anemia in cancer patients, such as bleeding, hemolysis, renal insufficiency, insufficient erythropoiesis caused by chronic inflammatory cytokines during carcinogenesis or myelosuppressive chemotherapy treatments, and nutrition deficiency $[4,8,22,23]$. In the current clinical setting, regardless of the different underlying causes of anemia, the evaluation of the severity of anemia mostly depends on the level of baseline $\mathrm{Hb}$. However, wide variations of $\mathrm{Hb}$ levels among cancer patients, or even the general population, have been extensively reported, making it difficult to diagnose anemia solely based on a single measurement of $\mathrm{Hb}$ level at baseline. The newest updated NCCN guideline suggested that a drop of as little as $2 \mathrm{~g} / \mathrm{dL}$ in $\mathrm{Hb}$ level, even in non-anemic patients with a high baseline $\mathrm{Hb}$ level, is an alarming indicator for the presence of anemia [3,24-26]. Nonetheless, as yet there has been no report systemically evaluating the role of postdiagnosis change of $\mathrm{Hb}$ level in predicting cancer patient survival. To the best of our knowledge, this is the first population-based study to assess the association between $\mathrm{Hb}$ change and overall patient survival in multiple cancers. Consistent with the suggestions from the NCCN guideline, our findings indicated that changes in $\mathrm{Hb}$ levels in cancer patients after diagnosis should be 


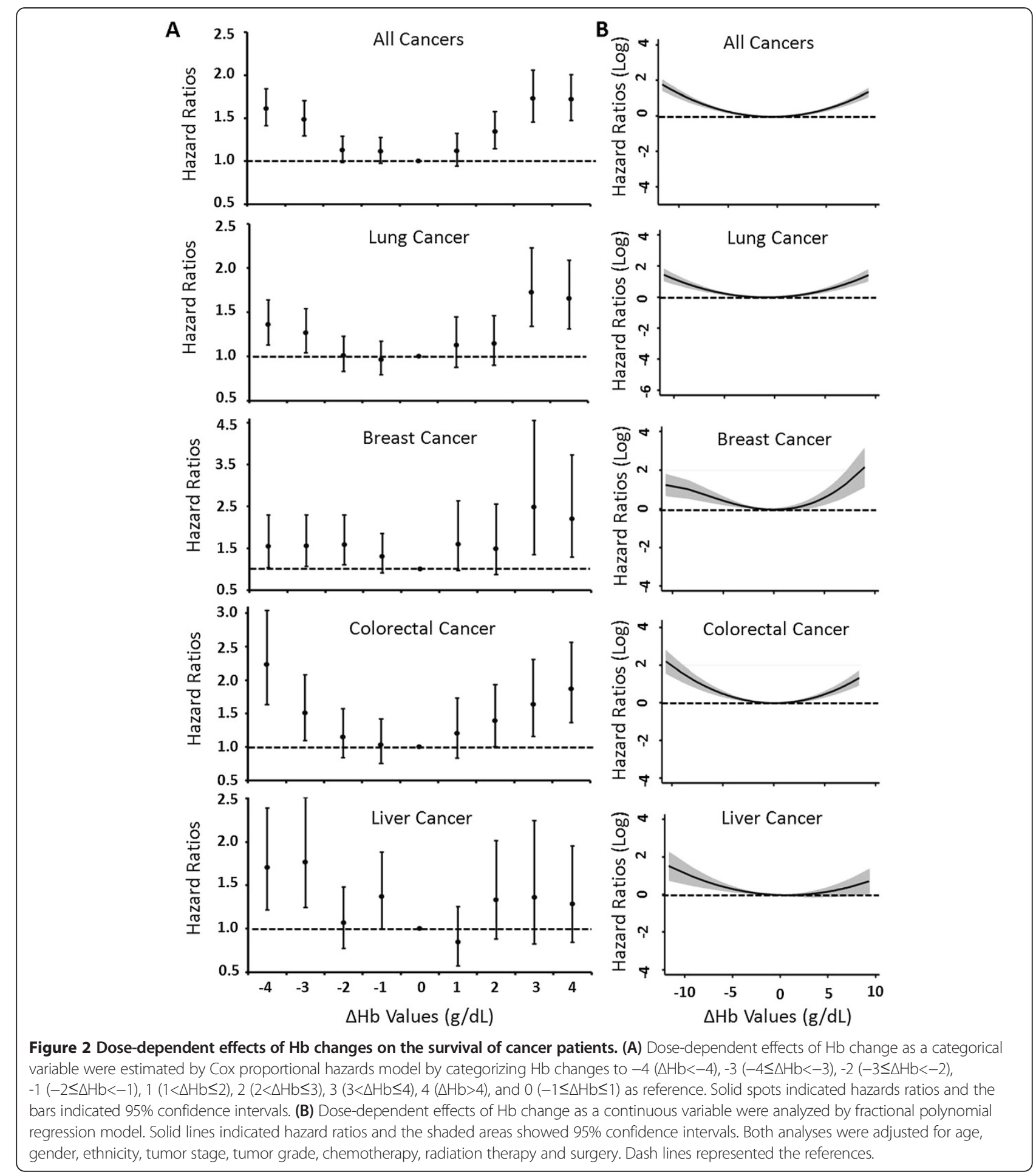

monitored and taken into consideration in the evaluation and determination of their treatment plans.

We noticed that both decreased and increased $\mathrm{Hb}$ levels were associated with a significantly poorer survival (Table 2 and Figure 2). The observation for decreased $\mathrm{Hb}$ was not surprising since at least a portion of $\mathrm{Hb}$ decrease might be accounted for by cancer- or treatment-related anemia. However, it was interesting to notice that an increase in $\mathrm{Hb}$ level, which usually indicates the alleviation of anemia, also conferred an increased risk of death. Moreover, in the analyses for four cancers combined, as well as individual lung cancer and 


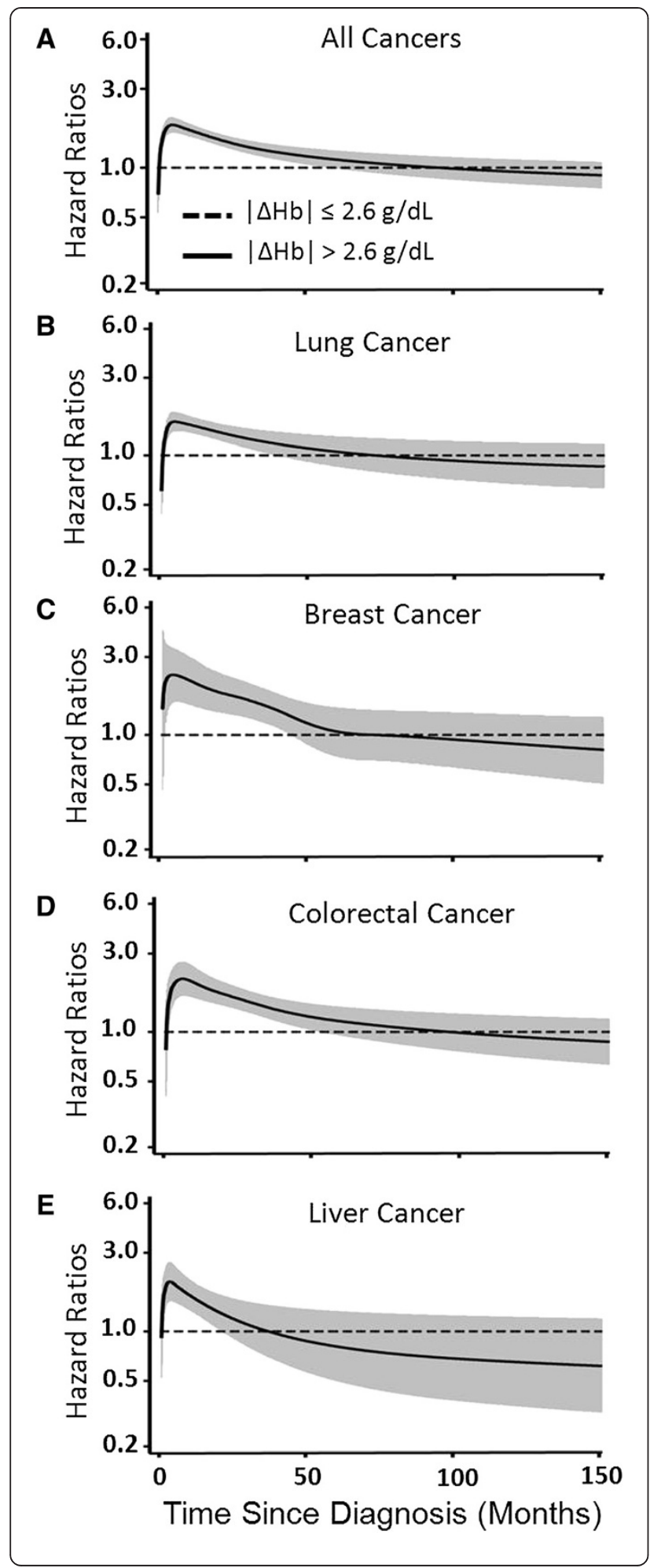

Figure 3 Time-dependent effects of $\mathrm{Hb}$ changes on the survival of cancer patients. Flexible parametric modeling framework was used to assess the effect by $\mathrm{Hb}$ changes on the overall survival of patients of (A) all cancers, (B) lung cancer, (C) breast cancer, (D) colorectal cancer, and (E) liver cancer. The analysis was adjusted for age, gender, ethnicity, tumor stage, tumor grade, chemotherapy, radiation therapy and surgery. Solid lines indicated hazard ratios and shaded areas showed the 95\% confidence intervals. Dash lines represented the references.

breast cancer, patients with an increased $\mathrm{Hb}$ level showed an even more prominent adverse survival compared to those with a decreased $\mathrm{Hb}$, with an $\mathrm{HR}$ of 1.53 versus $1.35,1.59$ versus 1.25 , and 1.65 versus 1.45 , respectively (Table 2). The mechanisms underlying these observations remain elusive. One potential explanation might be the use of anti-anemia medications such as ESAs or PBRC. There have been several recent studies highlighting the controversial clinical benefits and risks of using ESAs and/or PBRC to help alleviate cancer- or therapy-related anemia [9,11,12,27-30]. Some of these studies reported that overdose or over-duration in the treatment of anemia might result in elevated rate of patient death [9-12]. Our results indicated that a significant increase in $\mathrm{Hb}$ level after cancer diagnosis was associated with adverse patient survival, substantiating these previous reports using a population-based epidemiological approach. Nonetheless, it should be noted that although these observations are clinically plausible, they lack supports from solid clinical evidence since we currently do not have complete anemia treatment information from our chart review-derived database. Future studies with a more comprehensive collection of anemia diagnosis and treatment data are warranted to validate these hypotheses.

Clinically diagnosed anemia has been associated with unfavorable patient prognosis [31]. However, the current treatment of anemia does not always result in improved patient survival, suggesting additional criteria are needed in determining and monitoring the effects of antianemia therapies [32]. In the present study, we found that the significantly increased risk of death conferred by anemia was evident in those patients with a small $\mathrm{Hb}$ change of less than $4 \mathrm{~g} / \mathrm{dL}$, but not in those with an $\mathrm{Hb}$ change of more than $4 \mathrm{~g} / \mathrm{dL}$ (Figure 4 ). These results indicated that post-diagnosis $\mathrm{Hb}$ changes may help improve the decision making process of anemia correction treatment in clinical settings. Specifically, it raised the question whether anti-anemia medications should continuously be administered to patients with a relatively large change in $\mathrm{Hb}$ level in a short period of time. Nonetheless, since our analysis did not include anti-anemia treatments which could significantly confound the results, independent studies with more complete anti-anemia 


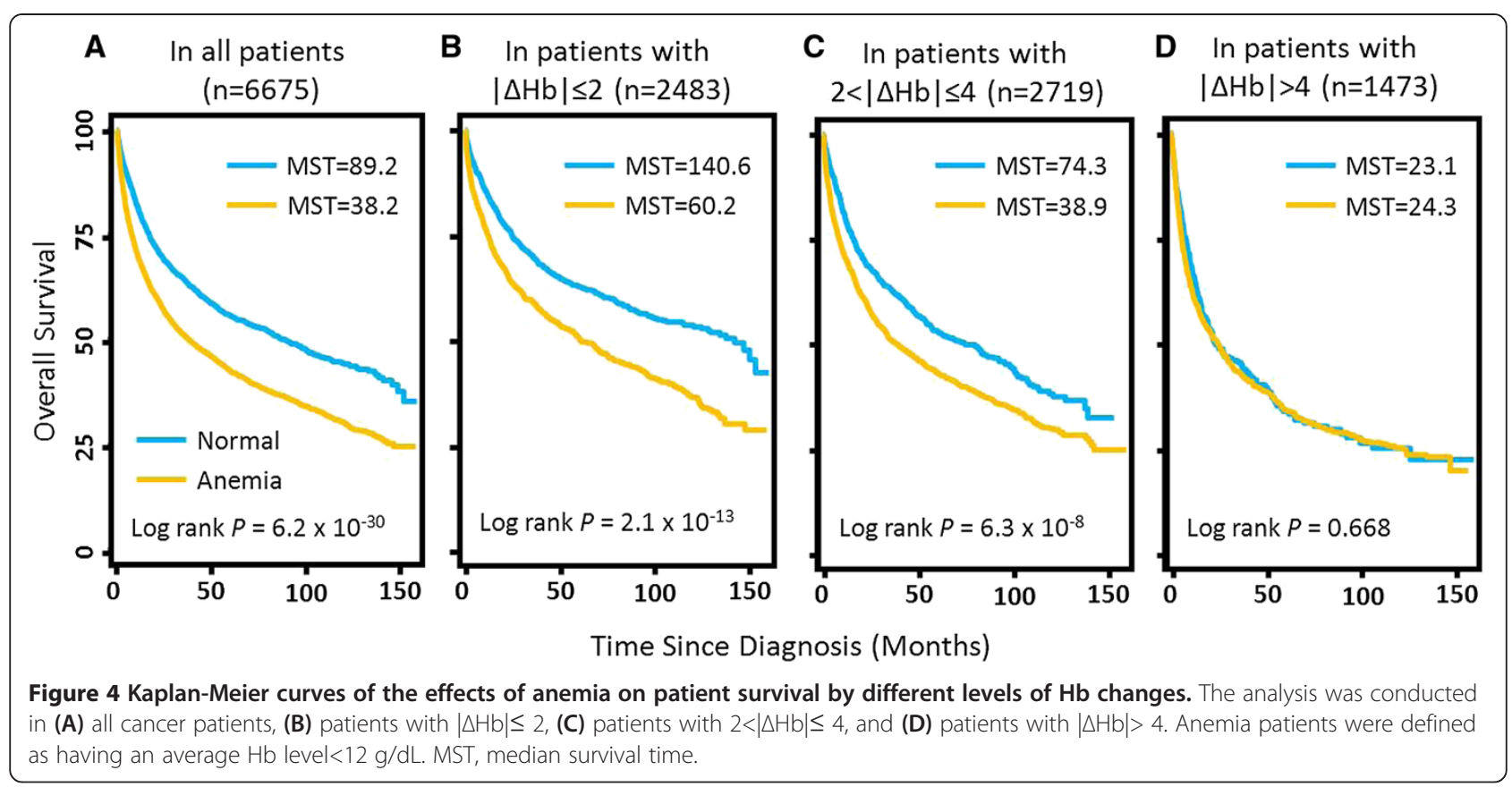

treatment data are needed to validate these findings with regard to their clinical relevance.

Although anemia is a ubiquitous comorbidity in cancer patients, its prevalence in different cancer types vary widely, ranging from $30 \%$ to $90 \%$ [1]. A recent large population-based study reported that CRC patients had the highest incidence of anemia at diagnosis among all solid tumors, whereas there was no apparent $\mathrm{Hb}$ change in CRC patients within five years before diagnosis [33]. In the present study, post-diagnosis $\mathrm{Hb}$ changes in CRC patients were most significantly associated with overall survival among the four cancer types, as evidenced by the $100 \%$ validations with $P<0.01$ in bootstrap resampling in the analyses of both $|\Delta \mathrm{Hb}|$ and $\Delta \mathrm{Hb}$ levels (Table 2). In comparison, for breast cancer, no significant results were validated for the association between $\Delta \mathrm{Hb}$ and patient survival. It remains to be determined as to whether gender played a role in these observations. We compared the $|\Delta \mathrm{Hb}|$ of breast cancer patients to that of female patients of the other three cancers and found that breast cancer patients had the smallest $\mathrm{Hb}$ changes among all female cancer patients $(P<0.001$ for all three comparisons, Figure 1). These differences were likely due to cancer type instead of gender status, because such significant differences were not identified between male and female patients in the other three cancers $(P=0.056,0.096$ and 0.850 for lung, colorectal and liver cancers, respectively, Figure 1). Although the mechanism underlying these cancer type-specific findings remains to be investigated, these data suggest that the use of $\mathrm{Hb}$ changes in anemia management and patient prognostication should be individually assessed for different cancer types.

There are several strengths in this study. We had a large population of 6675 patients from a single institute and our conclusions were consistent among four different cancer types. The study was focused on the extensive analysis of a single variable and, thus, did not have the multiple comparison issue. The findings were highly statistically significant in both the Cox regression and the log rank analyses with strict internal validations using bootstrap resampling, indicating that the possibility of false positive findings is unlikely. Meanwhile, our study also has limitations. Because this study used archived clinical data obtained from chart review instead of prospectively collected data, many cancer type-specific data did not have complete and/or standardized records in medical charts and thus had a relatively large percentage of missing values. In addition, important confounding variables such as anti-anemia modalities and treatment toxicities were not complete in our database and thus not adjusted in the multivariate analyses. Therefore, our data, although highly statistically significant and biologically plausible, need to be further substantiated in more rigorous studies using large independent and prospective populations with a more comprehensive collection of relevant confounding variables.

\section{Conclusions}

In summary, our findings suggested that post-diagnosis $\mathrm{Hb}$ changes, regardless of the baseline $\mathrm{Hb}$ levels and the direction of changes, associate with the overall survival 
of the patients of various cancers and should be taken into consideration in the tailored correction of anemia treatment. Since cancer- or treatment-related anemia is present in up to $90 \%$ of patients, our finding has considerable significance at the population level. Moreover, because $\mathrm{Hb}$ level is frequently measured in the routinely tested complete blood count panel, $\mathrm{Hb}$ changes may be a potentially important variable that can be incorporated with other host and clinical factors to build cancer prognosis assessment models.

\section{Additional files}

Additional file 1: Table S1. The association between baseline $\mathrm{Hb}$ leve and cancer survival. Table S2. Joint effect of baseline $\mathrm{Hb}$ level and $\mathrm{Hb}$ change on cancer overall survival.

Additional file 2: Figure S1. Kaplan-Meier curves of the effects of anemia on patient survival by different levels of $\mathrm{Hb}$ changes adjusting for all covariates. The analysis was conducted in (A) all cancer patients, (B) patients with $|\Delta H \mathrm{Hb}| \leq 2$, (C) patients with $2<|\Delta \mathrm{Hb}| \leq 4$, and (D) patients with $|\Delta \mathrm{Hb}|>4$. Anemia patients were defined as having an average $\mathrm{Hb}$ level<12 g/dL. The analyses were adjusting for age, gender, ethnicity, tumor stage, tumor grade, chemotherapy, radiation therapy and surgery. Figure S2. Kaplan-Meier curves of the effects of anemia on patient survival by different levels of $\mathrm{Hb}$ changes in individual cancer site. The analysis was conducted in (A) Lung cancer, (B) Breast cancer, (C) Colorectal cancer, and (D) Liver cancer. Anemia patients were defined as having an average $\mathrm{Hb}$ level $<12 \mathrm{~g} / \mathrm{dL}$. Figure S3. Kaplan-Meier curves of the effects of anemia on patient survival by actual changes of $\mathrm{Hb}$ level. The analysis was conducted in (A) patients with $-2 \leq \Delta \mathrm{Hb}<0$, (B) patients

with $-4 \leq \Delta \mathrm{Hb}<2$, (C) patients with $\Delta \mathrm{Hb}<-4$, (D) patients with $0 \leq \Delta \mathrm{Hb}$ $\leq 2$, (E) patients with $2<\Delta \mathrm{Hb} \leq 4$, and (F) patients with $\Delta \mathrm{Hb}>4$. Anemia patients were defined as having an average $\mathrm{Hb}$ level $<12 \mathrm{~g} / \mathrm{dL}$.

\section{Competing interests}

The authors declare that they have no competing interests

\section{Authors' contribution}

SW conducted data collection, study design and manuscript writing. YL conducted data analysis. RM contributed to study design and manuscript writing. BL conducted data analysis and manuscript writing. JP contributed to study design and manuscript writing. $A B$ contributed to study design and manuscript writing. GC contributed to study design, data analysis, and manuscript writing. JX contributed to study design and manuscript writing. HY conducted data collection, study design, data analysis, and manuscript writing. All authors read and approved the final manuscript.

\section{Acknowledgements}

The work was supported by a start-up fund from Thomas Jefferson University, National Cancer Institute Grants CA153099 and CA152703, and a Research Scholar Award from the V Foundation for Cancer Research.

\section{Author details}

'Division of Population Science, Department of Medical Oncology, Kimmel Cancer Center, Thomas Jefferson University, Philadelphia, PA 19107, USA. ${ }^{2}$ Department of Pathology, Thomas Jefferson University, Philadelphia, PA 19107, USA. ${ }^{3}$ Center for Human Genetics Research, Department of Molecular Physiology \& Biophysics, Vanderbilt University, Nashville, TN 37232, USA ${ }^{4}$ Center for Molecular Medicine, National Heart Blood Lung Institute, National Institutes of Health, Bethesda, MD 20892, USA. ${ }^{5}$ State Key Laboratory of Cancer Biology, Cell Engineering Research Centre \& Department of Cell Biology, Fourth Military Medical University, Xi'an 710032, China.

Received: 2 August 2012 Accepted: 5 July 2013

Published: 10 July 2013

\section{Reference}

1. Knight K, Wade S, Balducci L: Prevalence and outcomes of anemia in cancer: a systematic review of the literature. Am J Med 2004, 116(Suppl 7A):11S-26S

2. Ludwig H, Van Belle S, Barrett-Lee P, Birgegard G, Bokemeyer C, Gascon P, Kosmidis P, Krzakowski M, Nortier J, Olmi P, Schneider M, Schrijvers D: The European Cancer Anaemia Survey (ECAS): a large, multinational, prospective survey defining the prevalence, incidence, and treatment of anaemia in cancer patients. Eur J Cancer 2004, 40(15):2293-2306.

3. Rodgers GM, Becker PS, Blinder M, Cella D, Chanan-Khan A, Cleeland C, Coccia PF, Djulbegovic B, Gilreath JA, Kraut EH, Matulonis UA, Millenson MM, Reinke D, Rosenthal J, Schwartz RN, Soff G, Stein RS, Vlahovic G, Weir AB: Cancer- and Chemotherapy-Induced Anemia. Journal of the National Comprehensive Cancer Network 2012, 10(5):628-653.

4. Spivak JL: The anaemia of cancer: death by a thousand cuts. Nat Rev Cancer 2005, 5(7):543-555.

5. Caro JJ, Salas M, Ward A, Goss G: Anemia as an independent prognostic factor for survival in patients with cancer: a systemic, quantitative review. Cancer 2001, 91(12):2214-2221.

6. Hoff CM, Hansen HS, Overgaard M, Grau C, Johansen J, Bentzen J, Overgaard J: The importance of haemoglobin level and effect of transfusion in HNSCC patients treated with radiotherapy-results from the randomized DAHANCA 5 study. Radiother Oncol 2011, 98(1):28-33.

7. Schwartz RN: Anemia in patients with cancer: incidence, causes, impact, management, and use of treatment guidelines and protocols. Am J Health Syst Pharm 2007, 64(3 Suppl 2):S5-13. quiz S28-30.

8. Steensma DP: Is anemia of cancer different from chemotherapy-induced anemia? J Clin Oncol 2008, 26(7):1022-1024.

9. Bohlius J, Schmidlin K, Brillant C, Schwarzer G, Trelle S, Seidenfeld J, Zwahlen M, Clarke M, Weingart O, Kluge S, Piper M, Rades D, Steensma DP, Djulbegovic B, Fey MF, Ray-Coquard I, Machtay M, Moebus V, Thomas G, Untch M, Schumacher M, Egger M, Engert A: Recombinant human erythropoiesis-stimulating agents and mortality in patients with cancer: a meta-analysis of randomised trials. Lancet 2009, 373(9674):1532-1542.

10. Bohlius J, Langensiepen S, Schwarzer G, Seidenfeld J, Piper M, Bennett C, Engert $A$ : Recombinant human erythropoietin and overall survival in cancer patients: results of a comprehensive meta-analysis. $J$ Natl Cancer Inst 2005, 97(7):489-498.

11. Tonelli M, Hemmelgarn B, Reiman T, Manns B, Reaume MN, Lloyd A, Wiebe $\mathrm{N}$, Klarenbach S: Benefits and harms of erythropoiesis-stimulating agents for anemia related to cancer: a meta-analysis. CMAJ 2009, 180(11):E62-71.

12. Bennett $C L$, Silver $S M$, Djulbegovic B, Samaras AT, Blau CA, Gleason KJ, Barnato SE, Elverman KM, Courtney DM, McKoy JM, Edwards BJ, Tigue CC, Raisch DW, Yarnold PR, Dorr DA, Kuzel TM, Tallman MS, Trifilio SM, West DP, Lai SY, Henke M: Venous thromboembolism and mortality associated with recombinant erythropoietin and darbepoetin administration for the treatment of cancer-associated anemia. JAMA 2008, 299(8):914-924.

13. Ludwig H, Crawford J, Osterborg A, Vansteenkiste J, Henry DH, Fleishman A, Bridges K, Glaspy JA: Pooled analysis of individual patient-level data from all randomized, double-blind, placebo-controlled trials of darbepoetin alfa in the treatment of patients with chemotherapy-induced anemia. J Clin Oncol 2009, 27(17):2838-2847.

14. Glaspy J, Crawford J, Vansteenkiste J, Henry D, Rao S, Bowers P, Berlin JA, Tomita D, Bridges K, Ludwig H: Erythropoiesis-stimulating agents in oncology: a study-level meta-analysis of survival and other safety outcomes. Br J Cancer 2010, 102(2):301-315.

15. Aapro MS, Link H: September 2007 update on EORTC guidelines and anemia management with erythropoiesis-stimulating agents. Oncologist 2008, 13(Suppl 3):33-36.

16. Rizzo JD, Brouwers M, Hurley P, Seidenfeld J, Arcasoy MO, Spivak JL, Bennett CL, Bohlius J, Evanchuk D, Goode MJ, Jakubowski AA, Regan DH, Somerfield MR: American Society of Clinical Oncology/American Society of Hematology clinical practice guideline update on the use of epoetin and darbepoetin in adult patients with cancer. J Clin Oncol 2010, 28(33):4996-5010.

17. Scrijvers D, Roila F: Erythropoiesis-stimulating agents in cancer patients: ESMO recommendations for use. Ann Oncol 2009, 20(Suppl 4):159-161.

18. Steinbrook R: Erythropoietin, the FDA, and oncology. N Engl J Med 2007, 356(24):2448-2451

19. Henderson AR: The bootstrap: a technique for data-driven statistics. Using computer-intensive analyses to explore experimental data. Clinica chimica acta; international journal of clinical chemistry 2005, 359(1-2):1-26. 
20. Royston P: A strategy for modelling the effect of a continuous covariate in medicine and epidemiology. Statistics in medicine 2000, 19(14):1831-1847.

21. Lambert PC, Royston P: Further development of flexible parametric models for survival analysis. Stata Journal 2009, 9(2):265-290.

22. Weiss G, Goodnough LT: Anemia of chronic disease. N Engl J Med 2005, 352(10):1011-1023.

23. Groopman JE, Itri LM: Chemotherapy-induced anemia in adults: incidence and treatment. J Natl Cancer Inst 1999, 91(19):1616-1634.

24. Vakil N, Moayyedi P, Fennerty MB, Talley NJ: Limited value of alarm features in the diagnosis of upper gastrointestinal malignancy: systematic review and meta-analysis. Gastroenterology 2006, 131(2):390-401. quiz 659-360.

25. Twine RW, Morris C: Early detection of carcinomas of the right colon: role of hemoglobin and mean corpuscular volume. J Natl Med Assoc 1986, 78(3):187-192

26. Rai $S$, Hemingway D: Iron deficiency anaemia-useful diagnostic tool for right sided colon cancers? Colorectal Dis 2005, 7(6):588-590.

27. Untch M, Fasching PA, Konecny GE, von Koch F, Conrad U, Fett W, Kurzeder C, Luck HJ, Stickeler E, Urbaczyk H, Liedtke B, Salat C, Harbeck N, Muller V, Schmidt M, Hasmuller S, Lenhard M, Schuster T, Nekljudova V, Lebeau A, Loibl S, von Minckwitz G: PREPARE trial: a randomized phase III trial comparing preoperative, dose-dense, dose-intensified chemotherapy with epirubicin, paclitaxel and CMF versus a standard-dosed epirubicin/ cyclophosphamide followed by paclitaxel +/- darbepoetin alfa in primary breast cancer--results at the time of surger. Ann Oncol 2011 22(9):1988-1998.

28. Rodgers GM: A perspective on the evolution of management of cancerand chemotherapy-induced anemia. J Natl Compr Canc Netw 2012, 10(4):434-437.

29. Khorana AA, Francis CW, Blumberg N, Culakova E, Refaai MA, Lyman GH: Blood transfusions, thrombosis, and mortality in hospitalized patients with cancer. Arch Intern Med 2008, 168(21):2377-2381.

30. Leyland-Jones B, Semiglazov V, Pawlicki M, Pienkowski T, Tjulandin S, Manikhas G, Makhson A, Roth A, Dodwell D, Baselga J, Biakhov M, Valuckas K, Voznyi E, Liu X, Vercammen E: Maintaining normal hemoglobin levels with epoetin alfa in mainly nonanemic patients with metastatic breast cancer receiving first-line chemotherapy: a survival study. J Clin Oncol 2005, 23(25):5960-5972.

31. Musallam KM, Tamim HM, Richards T, Spahn DR, Rosendaal FR, Habbal A Khreiss M, Dahdaleh FS, Khavandi K, Sfeir PM, Soweid A, Hoballah JJ, Taher AT, Jamali FR: Preoperative anaemia and postoperative outcomes in noncardiac surgery: a retrospective cohort study. Lancet 2011, 378(9800):1396-1407.

32. Glaspy J: Update on safety of ESAs in cancer-induced anemia. J Nat/ Compr Canc Netw 2012, 10(5):659-666.

33. Edgren G, Bagnardi V, Bellocco R, Hjalgrim H, Rostgaard K, Melbye M, Reilly $\mathrm{M}$, Adami HO, Hall P, Nyren O: Pattern of declining hemoglobin concentration before cancer diagnosis. Int J Cancer 2010, 127(6):1429-1436

doi:10.1186/1471-2407-13-340

Cite this article as: Wan et al:: Post-diagnosis hemoglobin change associates with overall survival of multiple malignancies - results from a 14-year hospital-based cohort of lung, breast, colorectal, and liver cancers. BMC Cancer 2013 13:340.

\section{Submit your next manuscript to BioMed Central and take full advantage of:}

- Convenient online submission

- Thorough peer review

- No space constraints or color figure charges

- Immediate publication on acceptance

- Inclusion in PubMed, CAS, Scopus and Google Scholar

- Research which is freely available for redistribution 